\title{
Sea ice dynamics in the Weddell Sea simulated with an optimized model
}

\author{
Markus Harder \\ Institut für Meereskunde an der Universität Kiel, Kiel, Germany \\ Holger Fischer \\ Alfred-Wegener-Institut für Polar- und Meeresforschung, Bremerhaven, Germany
}

\begin{abstract}
The advection of sea ice and associated freshwater/salt fluxes in the Weddell Sea in 1986 and 1987 are investigated with a large-scale dynamicthermodynamic sea ice model. The model is validated and optimized by comparison of simulated sea ice trajectories with observed drift paths of six buoys deployed on the Weddell Sea ice. The skill of the model is quantified by an error function that measures the deviaitions of simulated trajectories from observed 30-day sea ice drift. A large number of sensitivity studies show how simulated sea ice transports and associated freshwater/salt fluxes respond to variations in physical parameterizations. The model reproduces the observed ice drift well, provided ice dynamics parameters are set to appropriate values. Optimized values for the drag coefficients and for the ice strength parameter are determined by applying the error function to various sensitivity studies with different parameters. The optimized model yields a mean northward sea ice volume export out of the southern Weddell Sea of $1693 \mathrm{~km}^{3}$ in 1986 and $2339 \mathrm{~km}^{3}$ in 1987 . This shows the important role of sea ice transport for the freshwater budget of the Weddell Sea and gives an indication of its high interannual variability.
\end{abstract}

\section{Introduction}

Sea ice covering the polar seas strongly affects the exchanges of heat and freshwater between ocean and atmosphere. The drift of sea ice significantly modifies the extent and spatial thickness distribution of the ice pack. Large transports of freshwater are associated with this sea ice advection, as well as transports of latent heat which result from the spatial distribution of sea ice melting and freezing. The release of brine in freezing regions and of freshwater in melting regions of sea ice plays an important role in the driving mechanisms of the thermohaline ocean circulation. These effects of sea ice are especially important in the Weddell Sea and in the Greenland Sea.

A growing number of climate models include a sea ice component to take into account the dynamic and thermodynamic effects of this part of the cryosphere. It is necessary to obtain observations of sea ice drift, to include these processes in climate models, and to verify the models in comparison with the observations from drifting buoys and satellite-borne remote sensing. This study investigates the freshwater fluxes linked with sea

Copyright 1999 by the American Geophysical Union.

Paper number 1999JC900047.

0148-0227/99/1999JC900047\$09.00 ice drift in the Weddell Sea in 1986 and 1987 and verifies the simulation by comparison with observed buoy tracks. An error function quantifies the deviation between model and observations. It is used to optimize the model parameters, such as drag coefficients and ice strength, which affect the simulated ice transport. For the Weddell Sea, comparisons of model results with observations are rare and often limited to much smaller data sets than used here [e.g., Hibler and Ackley, 1983; Fischer and Lemke, 1994; Harder and Lemke, 1994].

\section{Physical Sea Ice Model}

Sea ice is considered a two-dimensional continuum as in widely used dynamic-thermodynamic sea ice models [e.g., Hibler, 1979; Flato and Hibler, 1990; Stössel, 1991; Fischer and Lemke, 1994; Harder and Lemke, 1994; Kreyscher et al., 1997]. Thermodynamic growth and decay of the ice occurs according to the energy balance model of Parkinson and Washington [1979] with the zero-layer assumption for heat conduction through the ice [Semtner, 1976]. A prognostic snow layer is included [Owens and Lemke, 1990]. Oceanic heat flux is calculated by the prognostic mixed layer model of Lemke et al. [1990]. Sea ice drift is derived from a momentum equation with a viscous-plastic rheology [Hibler, 1979]

$$
m \frac{d \mathbf{u}}{d t}=\tau_{a}+\tau_{w}+\mathbf{F}+\mathbf{C}+\mathbf{T}
$$


where $m$ is the ice mass per area, $m d \mathbf{u} / d t$ is the temporal change in momentum, $\tau_{a}$ is wind stress, $\tau_{w}$ is oceanic stress, $\mathbf{F}$ is internal forces due to ice deformation, $\mathbf{C}$ is Coriolis force, and $\mathbf{T}$ is the force due to sea surface tilt $\nabla H$. The very small, nonlinear term of momentum advection is neglected. Equation (1) is solved in the numerical model.

The ice drift follows changes in forcing within a few hours [McPhee, 1980]. Therefore the acceleration term $m d \mathbf{u} / d t$ on the left-hand side of (1) is small compared to the larger terms on the right-hand side as long as timescales not shorter than a day are considered [Harder, 1996]. Also, the force $\mathbf{T}$ due to sea surface tilt is small [Harder, 1996; Steele et al., 1997].

The essential forces affecting ice motion are the wind stress on the top and the oceanic stress at the bottom. In regions with strong ice deformation, internal forces $\mathbf{F}$ are the third important term [Hibler, 1979; Harder, 1996; Steele et al., 1997].

According to boundary layer parameterizations [McPhee, 1979], atmospheric stress is described as

$$
\tau_{a}=\rho_{a} c_{a}\left|\mathbf{u}_{a}\right| \mathbf{R}_{\phi} \mathbf{u}_{a}
$$

and similarly the oceanic stress is described as

$$
\tau_{w}=\rho_{w} c_{w}\left|\mathbf{u}_{w}-\mathbf{u}\right| \mathbf{R}_{\theta}\left(\mathbf{u}_{w}-\mathbf{u}\right)
$$

where $\rho_{a}=1.3 \mathrm{~kg} \mathrm{~m}^{-3}$ and $\rho_{w}=1025 \mathrm{~kg} \mathrm{~m}^{3}$ are the densities of air and water, respectively, $c_{a}$ and $c_{w}$ are the drag coefficients, and $\mathbf{u}_{a}$ and $\mathbf{u}_{w}$ are wind and ocean current velocities, respectively. $\mathbf{R}$ is an orthogonal matrix that describes the deflection angles between drag and velocity of the forcing medium. These angles are $\phi=0^{\circ}$ for the surface wind and $\theta=25^{\circ}$ [McPhee, 1979] for the geostrophic ocean current.

A reasonable physical model of the internal forces $\mathbf{F}$ treats sea ice as a plastic medium [Campbell, 1965]. Hibler [1979], whose model we apply here, gives a formulation of a (viscous-)plastic rheology describing the internal forces in sea ice as the divergence of a stress tensor. These forces due to ice deformation are proportional to the ice strength $P$, which is given in $\mathrm{Nm}^{-1}$. It is described as the empirical function [Hibler, 1979]

$$
P(h, A)=P^{*} h \exp (-20(1-A))
$$

The ice strength $P$ increases linearly with the mean ice thickness $h$ and exponentially with the ice concentration $A$, which ranges from 0 to 1 . It is proportional to the ice strength parameter $P^{*}$, which is given in $\mathrm{N} \mathrm{m}^{-2}$. The Coriolis force

$$
\mathbf{C}=m f \mathbf{R}_{-\pi / 2} \mathbf{u}
$$

causes a modification in ice drift direction but has only minor impact on the drift speed [Kottmeier et al., 1992]. $f$ is the Coriolis parameter. Under free drift conditions with negligible internal ice interaction, for example, in summer, the balance of the three forces

$$
\tau_{a}+\tau_{w}+\mathbf{C}=0
$$

is a good approximation of sea ice drift [ $M c P h e e, 1980$; Thorndike and Colony, 1982]. An analytical description of free drift is given by $M c P h e e$ [1980]. While the simplified equation (6) illustrates the balance of the important terms of the momentum equation, the full momentum equation (1) is applied in the model.

The model domain extends from $60^{\circ} \mathrm{W}$ to $60^{\circ} \mathrm{E}$ and from $80^{\circ} \mathrm{S}$ to $47.5^{\circ} \mathrm{S}$ in the Weddell Sea sector of the Southern Ocean. Daily forcing data for surface winds are taken from European Centre for Medium-Range Weather Forecasts (ECMWF) analyses at the $1000-\mathrm{hPa}$ level from 1986 and 1987 [Trenberth and Olson, 1988]. Air temperature and humidity are also derived from ECMWF data according to Fischer and Lemke [1994]. Cloud coverage, precipitation, and ocean currents are climatological annual means as described by Fischer and Lemke [1994]. A cyclostationary state of the ice cover is reached after five repeated spin-up years with 1986 forcing followed by the 1986 and 1987 forcing applied for two more years. The final state of the model does not significantly depend on the initial conditions and the spin-up process. A more detailed description of the model and the forcing data is given by Fischer and Lemke [1994], Harder and Lemke [1994], and Horder et al. [1998]. Hibler [1979, appendix A] and Stössel et al. [1990] explain the numerical implementation.

\section{Model Parameters and Measurements}

The three most important forces controlling sea ice drift are each proportional to a corresponding parameter: wind stress $\tau_{a}$ relates to the atmospheric drag coefficient $c_{a}$, oceanic stress $\tau_{w}$ relates to the oceanic drag coefficient $c_{w}$, and internal forces $\mathbf{F}$ relate to the ice strength parameter $P^{*}$. A realistic simulation of ice drift requires that appropriate values for $c_{a}, c_{w}$, and $P^{*}$ be used.

There are some measurements of atmospheric drag in polar regions, rather few observations of oceanic drag under sea ice, and practically no direct methods to determine the large-scale ice strength. Measurements are restricted to relatively small areas and short time periods, and they give different results for different regions, seasons, and years [e.g., Overland, 1985; Smith, 1988; Overland and Colony, 1994; Tremblay and Mysak, 1997].

Large-scale climate models do not resolve all smallscale processes that control the momentum fluxes in specific situations. They usually use constant, representative mean parameter values. It is not a priori clear which values provide for a simulation closest to the observed state of the climate system. Our approach is to estimate reasonable intervals for $c_{a}, c_{w}$, and $P^{*}$ from measurements, to vary the parameters within these intervals, to compare the simulation results with observed 
buoy drift, and to find an optimized parameter set by minimizing an error function.

\subsection{Atmosphere-Ice Momentum Flux}

Measurements of atmosphere-ice momentum flux are difficult in polar regions. First, as the large-scale wind drag on the ice cover is the average effect of many smallscale turbulent processes, these have to be sampled over long time periods for reliable estimates of the effective drag [Overland, 1985]. However, in the hardly accessible polar regions, and especially in the Southern Ocean, measurements are sparse and usually short [Andreas et al., 1993].

Second, the magnitude of vertical momentum transfer depends on several local conditions: stratification and stability of the atmospheric boundary layer [Stössel, 1991; Overland and Colony, 1994], floe size, geometry and roughness [Arya, 1975; Hanssen-Bauer and Gjessing, 1988; Steele et al., 1989; Hartmann et al., 1994; Mai et al., 1996], and properties of the snow cover [Andreas and Claffey, 1995]. As sea ice in the Antarctic is generally thinner, younger, and less deformed than Arctic sea ice, comparatively smaller values for the vertical momentum flux and thus for the drag coefficients are usually found in the Antarctic [Overland, 1985].

The overview of Smith [1988] shows that atmospheric drag coefficients $c_{a}$ over sea ice have been observed in the range between about $1 \times 10^{-3}$ and $6 \times 10^{-3}$. McPhee [1980], refering to E. Leavitt (personal communication), cites a value of $c_{a}=2.7 \times 10^{-3}$ for winds at $10-\mathrm{m}$ height in the Arctic in summer. Aircraft measurements in the marginal ice zone of Fram Strait [Hartmann et al., 1994; Mai et al., 1996] show a dependence of the drag coefficient on the ice concentration with $c_{a}=1.3 \times 10^{-3}$ for open water, a maximum value of $2.6 \times 10^{-3}$ for ice concentrations between $50 \%$ and $60 \%$, and $1.8 \times 10^{-3}$ for completely ice-covered areas. Andreas et al. [1984] find maximum values of $c_{a}=4.0 \times 10^{-3}$ for the marginal ice zone of Bering Strait. Wamser and Martinson [1993] derive $10-\mathrm{m}$ air-ice drag coefficients of $1.79 \times 10^{-3}$ and $1.45 \times 10^{-3}$ from two measurement campaigns in the Winter Weddell Sea Project 1986 and the Winter Weddell Gyre Study 1989. Andreas et al. [1993] and Andreas and Claffey [1995] give a range of $1.1 \times 10^{-3}$ to $2.54 \times 10^{-3}$, depending on ice roughness, from measurements in the Weddell Sea.

An appropriate value of $c_{a}$ for forcing sea ice models is not obvious. Hibler [1979] uses an atmospheric drag coefficient of $1.2 \times 10^{-3}$. This value has since been widely used in sea ice simulations. However, we as several other authors also suggest that $c_{a}$ be adapted to the characteristics of the applied atmospheric forcing, for example, to take into account that surface winds are weaker than geostrophic winds. Depending on the type of model and forcing, values for $c_{a}$ in modeling studies are, for example, $0.8 \times 10^{-3}$ [Preller and Posey, 1989], $1.55 \times 10^{-3}$ [Lu et al., 1990], and $2.8 \times 10^{-3}$ [Overland and Pease, 1988]. Stössel [1992] uses an atmospheric drag coefficient of $2.7 \times 10^{-3}$ for the standard simulation. He argues that the atmospheric drag coefficient should be half the oceanic drag coefficient $c_{w}$ according to McPhee [1980] and Leppäranta [1981]. Accordingly, Harder [1994] uses a 10-m atmospheric drag coefficient of $1.5 \times 10^{-3}$ and an oceanic drag coefficient of $c_{w}=2 c_{a}=3.0 \times 10^{-3}$.

Stössel and Claussen [1993] use a prognostic atmospheric boundary layer model to force the sea ice drift in a model for the Southern Ocean. They find a high spatial variability of the atmospheric drag coefficient ranging between $10^{-4}$ and $3.6 \times 10^{-3}$. Sensitivity studies of Holland et al. [1993] with extreme values of $1.2 \times 10^{-4}$ and $1.2 \times 10^{-2}$ show the strong impact of the drag coefficient on ice dynamics. Chapman et al. [1994] vary the atmospheric drag coefficient $c_{a}$ between 0 and $1.7 \times 10^{-3}$ for multivariate sensitivity studies.

\subsection{Ice-Ocean Momentum Flux}

The uncertainty about the ice-ocean drag coefficient $c_{w}$ is even larger because direct flux measurements in the oceanic boundary layer underneath the ice are rare [McPhee and Martinson, 1994]. An often cited value is $c_{w}=5.5 \times 10^{-3}$, determined during a 1975 Arctic Ice Dynamics Joint Experiment campaign in the Arctic [McPhee, 1980]. McPhee and Smith [1976] cite a significantly smaller value of $3.4 \times 10^{-3}$ for a 1972 campaign. McPhee and Smith also show that the choice between linear or quadratic drag parameterization for the evaluation of the data makes a difference of more than $25 \%$ in the obtained value for $c_{w}$. Kottmeier and Engelbart [1992] find a mean $c_{w}=3.05 \times 10^{-3}$ in a coastal polynya of the Weddell Sea applying a quadratic water stress law. Wamser and Martinson [1993] derive a much smaller value of $c_{w}=1.13 \times 10^{-3}$ that is even smaller than their estimate of the atmospheric drag coefficient $c_{a}$.

\subsection{Ice Strength}

A similar problem occurs for the ice strength parameter $P^{*}$ that controls the magnitude of the internal ice stress. Despite 2 decades of research, no generally applicable way has been found to determine the large-scale ice strength parameter $P^{*}$ directly from observations. Because the ice strength varies over several orders of magnitude from scales of meters to hundreds of kilometers [Campbell, 1965], laboratory experiments do not provide adequate estimates of large-scale ice strength which is the statistical result of a large number of interactions between individual floes. It depends on smallscale properties such as ice type, floe size, lead orientation etc. that are not resolved in large-scale models or observations. The problem of an appropriate icestrength parameterization for the internal forces is analogous to finding suitable viscosities for large-scale ocean models. (The formal description of internal ice strength 
follows the concept of frictional forces in fluids, with the modification that the ice viscosities are not constant but are highly nonlinear functions of the spatial derivatives of the velocity field [e.g., Hibler, 1979]). Some estimates of strain and deformation in pack ice have been made from a few field experiments with arrays of buoys or sensors [e.g., Richter-Menge, 1997; Geiger et al., 1998], but no conclusive value of $P^{*}$ has been derived. A common modeling approach to determine an appropriate $P^{*}$ is to run a number of simulations with different values and then to search for the most reasonable drift pattern [e.g., Ip, 1993]. While most previous model evaluations for the Southern Ocean have been done in a rather qualitative manner, we extend those studies by applying a quantitative error function.

\section{Observed Sea Ice Drift}

Several drift buoys were deployed on ship cruises during the simulated time period 1986 and 1987, most of them during the Winter Weddell Study Project 86 [Hoeber and Gube-Lehnhardt, 1987; Kottmeier and Hartig, 1990; Rowe et al., 1989; Hoeber, 1991]. Observed sea ice drift data are available from Argos drift buoys [Argos Collect Localisation Satellites Company, 1988] placed on ice floes. Table 1 shows the identification numbers, approximate lifetimes, and starting positions of the buoys used for model validation. These buoys drifted in icecovered regions of the Weddell Sea longer than a full seasonal cycle.

Positions of the Argos buoys are usually obtained several times per day with an accuracy of about $350 \mathrm{~m}$ [Argos Collect Localisation Satellites Company, 1988; Rowe et al., 1989]. A mean daily buoy position, in accordance with the time step of the model, is derived as an average of all observed positions for each day and buoy. The error of the calculated daily buoy drift speed is normally smaller than $0.006 \mathrm{~m} \mathrm{~s}^{-1}$. This is more than an order of magnitude smaller than the daily mean sea ice drift speed for the Weddell Sea, which is typically in the range of 0.1 to $0.15 \mathrm{~m} \mathrm{~s}^{-1}$ [Kottmeier et al., 1992; Fischer, 1995; Kottmeier and Sellmann, 1996]. Drift speeds averaged over several days, as used below, have even higher accuracies because the errors in the located positions become less relevant the farther the buoys drifted.

Table 1. Identification Numbers of the Drifting Sea Ice Buoys Used for Model Validation, Their Approximate Drift Periods, and Their Starting Positions in the Weddell Sea in 1986 and 1987

\begin{tabular}{rll}
\hline Buoy & Drift Period & Start \\
\hline 534 & Feb. 1986 to Apr. 1987 & $75.5^{\circ} \mathrm{S} 50.0^{\circ} \mathrm{W}$ \\
3311 & Oct. 1986 to Dec. 1987 & $69.2^{\circ} \mathrm{S} 5.9^{\circ} \mathrm{W}$ \\
3312 & Oct. 1986 to Dec. 1987 & $70.6^{\circ} \mathrm{S} 10.5^{\circ} \mathrm{W}$ \\
3313 & Oct. 1986 to Dec. 1987 & $70.0^{\circ} \mathrm{S} 6.9^{\circ} \mathrm{W}$ \\
3314 & Oct. 1986 to Dec. 1987 & $72.4^{\circ} \mathrm{S} 20.9^{\circ} \mathrm{W}$ \\
3316 & Oct. 1986 to Dec. 1987 & $70.6^{\circ} \mathrm{S} 16.6^{\circ} \mathrm{W}$ \\
\hline
\end{tabular}

\section{Simulated Trajectories}

Trajectories of sea ice drift are derived from the simulated Eulerian ice velocities for comparison with observed buoy tracks. They are calculated by setting their start position and date to those of the observed buoy and then successively calculating the movement of a hypothetical ice particle for each time step. The Fourthorder Runge-Kutta method is applied to interpolate trajectories from simulated ice velocity fields. (A sensitivity study with the simpler method of a single forward Euler step in time and a bilinear interpolation in space shows no significant differences in simulation results.)

While the method of simulated trajectories has been applied by some authors [e.g., Piacsek et al., 1991; Harder, 1996], many previous publications concerned with verifications of simulated ice drift [e.g., Hibler and Ackley, 1983; Ip et al., 1991; Vihma and Launiainen, 1993; Flato and Hibler, 1995; Geiger et al., 1998] use progressive vector plots to compare observed buoy drift with the simulation. Progressive vector plots use the observed (i.e., prescribed) buoy positions to calculate the ice drift. In contrast, simulated trajectories use the simulated (i.e., predicted) buoy positions. Because no information on the observed trajectory enters the calculation of the simulated trajectory that relies only on its own predicted positions, this is a much more rigorous test of simulated ice drift than progressive vector plots [Harder, 1997].

Our approach to verify and optimize the model is achieved by splitting the trajectories into segments, calculating the deviation between simulation and observation for each segment, and minimizing the mean error by variations of model parameters. Segments of simulated trajectories through 30 days each are considered for the error function. While this method is more demanding than progressive vector plots that prescribe the mean position, it excludes deviations in ice drift due to insufficiencies in the simulation more than 30 days ago.

Figure 1 shows examples of simulated and observed 30-day trajectories of sea ice drift. Observations are taken from buoy 534 (May-December 1986) and buoy 3311 and buoy 3316 (both April-December 1997). The dots indicate the intersections between 30-day intervals of the observed buoy tracks. Each simulated trajectory "starts" at one of these dots and "tries" to follow the path of the observed buoy to the successive dot as closely as possible.

The comparison between these simulated and observed trajectories, that is, the "trees" in Figure 1, shows a generally good agreement. The "branches" of the simulated 30-day trajectories are generally not far from the "trunk" that represents the observations. In most cases, the simulated buoys drift approximately in the same direction and with a comparable speed as the observed buoys. Several small-scale features of ice drift, such as loops and deviations from the mean drift direc- 


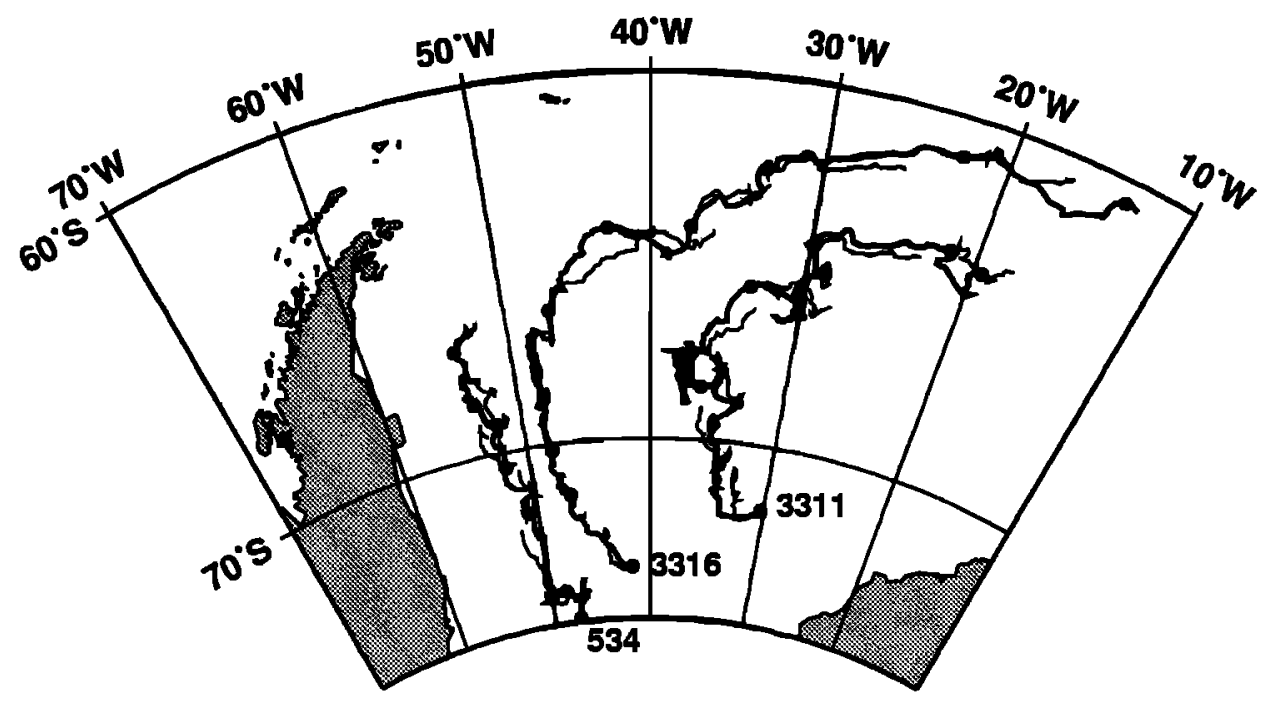

Figure 1. Observed buoy tracks (bold) and simulated 30-day trajectory segments (thin) for buoys 534,3311 , and 3316. Each dot indicates the beginning of a 30-day segment. The simulation is run with optimized parameters $c_{a}=1.6 \times 10^{-3}, c_{w}=4.5 \times 10^{-3}$, and $P^{*}=20,000 \mathrm{~N} \mathrm{~m}^{-2}$.

tion, are reproduced by the model. However, differences between simulated trajectories and observations remain for several reasons: (1) There are errors in the measurements of buoy positions, (2) Natural diffusion of sea ice occurs. Two buoys deployed at close locations tend to drift apart with time. (3) There are errors in the forcing fields, which are especially important for the wind field and ocean currents. Only few observations are available for the Weddell Sea. (4) There are insufficiencies of the physical sea ice model. Because a large-scale model is used to calculate processes on subgrid scales, specific local conditions are smoothed out. Considering these errors, the agreement between simulated and observed trajectories is remarkably good.

Simulated trajectories in Figure 1 are obtained from a simulation with optimized model parameters for the Weddell Sea: $c_{a}=1.6 \times 10^{-3}, c_{w}=4.5 \times 10^{-3}$ and $P^{*}=$ $20,000 \mathrm{~N} \mathrm{~m}^{-2}$. The optimization procedure is described in section 6 . The simulated trajectories are sensitive to changes in forcing and in model parameters. Figure 2 shows two modified simulations for buoy 534 with drag coefficients $c_{a}=1.3 \times 10^{-3}$ and $c_{w}=5.5 \times 10^{-3}$ (Figure 2a) similar to the values used by Hibler [1979] for his Arctic model and $c_{a}=c_{w}=2.5 \times 10^{-3}$ (Figure $2 b)$. In the case shown in Figure 2a, the ratio of the drag coefficients $c_{a} / c_{w} \approx 0.24$ is significantly smaller than in the standard simulation, and thus the atmospheric forcing is reduced whereas the friction in the ocean is increased. The opposite case shown in Figure $2 \mathrm{~b}$ has a very high ratio $c_{a} / c_{w}=1$ and thus strong atmospheric forcing together with weak oceanic friction. In both cases, the differences between simulated and observed trajectories increase significantly compared to the standard run (Figure 1). The simulated trajectories in Figure 2a are much shorter than the observed ones indicating that the ice drift is too slow, while in Figure
$2 \mathrm{~b}$ the simulated trajectories are too long and the ice drift is too fast.

Another sensitivity study with two modified simulations investigates the effect of the ice strength parameter $P^{*}$ on simulated trajectories. The drag coefficients are kept at their standard values, but the ice strength parameter $P^{*}$ is set to (1) 10,000 and (2) $40,000 \mathrm{~N} \mathrm{~m}^{-2}$. The simulated trajectories for the five buoys $(3311,3312,3313,3314$, and 3316) in the central and eastern Weddell Sea are not strongly affected by

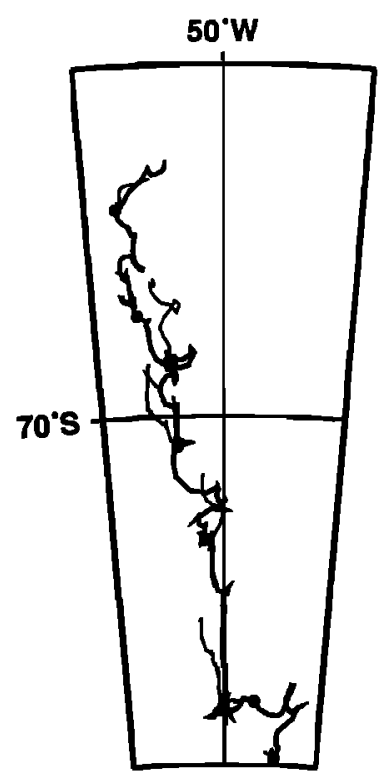

(a)

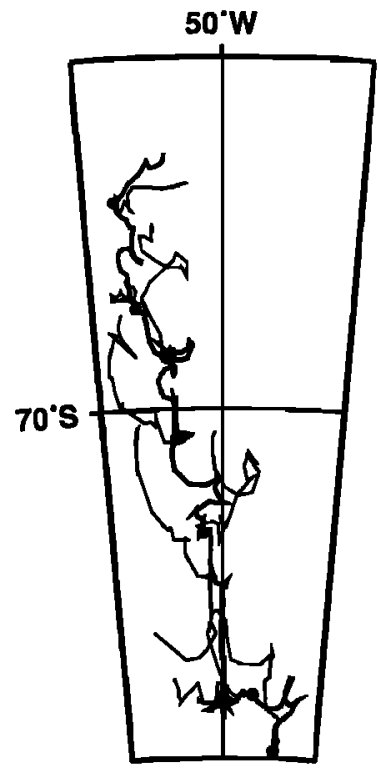

(b)
Figure 2. Observed buoy tracks (bold) and simulated 30-day trajectory segments (thin) for buoy 534 with drag coefficients (a) $c_{a}=1.3 \times 10^{-3}$ and $c_{w}=5.5 \times 10^{-3}$ and (b) $c_{a}=c_{w}=2.5 \times 10^{-3}$. 
the ice strength parameter $P^{*}$. In the central Weddell Sea, the mean ice motion is mostly divergent, and internal forces add, in the long-term mean, only minor contributions to the momentum balance (1) [Massom, 1992]. In contrast, the simulated trajectory of buoy 534 depends much more strongly on the ice strength parameter $P^{*}$, because both convergence (i.e., negative divergence) and shear are quite large in this region close to the coast of the Antarctic Peninsula.

Figure 3 shows the results for reduced (Figure 3a) and increased (Figure $3 \mathrm{~b}$ ) ice strength parameter $P^{*}$. The stronger the ice strength is, the slower the ice drift is. As buoy 534 passes through the thick ice in the western Weddell Sea along the Antarctic Peninsula, the internal forces counteracting the external forcing are especially important. However, under conditions of severe storms, the internal forces may reach considerable magnitude also in the central Weddell Sea. Because of the high variability of the wind field on daily to decadal timescales, the areas of strong convergence and/or shear vary much with time. Ice deformation may affect almost any region in the long run but not with the same magnitude. As all six buoys are somehow affected by variations in the ice strength parameter $P^{*}$, they are therefore all included in our sensitivity studies.

\section{Error Function}

Previous studies [e.g., Hibler, 1979; Hibler and Ackley, 1983; Stössel et al., 1990; Owens and Lemke, 1990; Stössel, 1992; Holland et al., 1993; Fischer and Lemke, 1994; Drinkwater et al., 1995; Harder et al., 1998 ] have

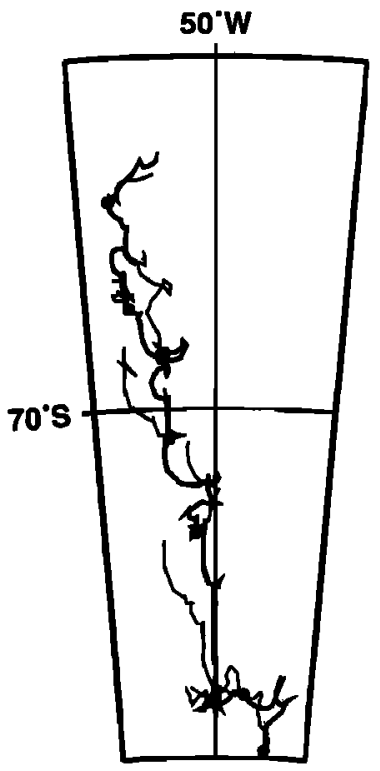

(a)

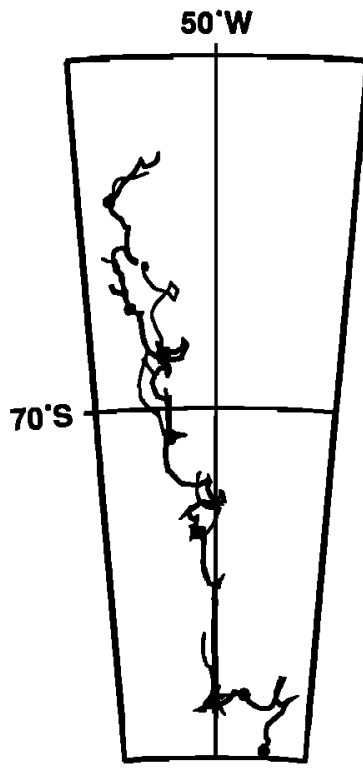

(b)
Figure 3. Observed buoy tracks (bold) and simulated 30 -day trajectory segments (thin) for buoy 534 . The ice strength parameter $P^{*}$ is (a) reduced to $10,000 \mathrm{~N} \mathrm{~m}^{-2}$ and (b) increased to $40,000 \mathrm{~N} \mathrm{~m}^{-2}$. Drag coefficients are kept at their standard values. shown how strongly sea ice simulations depend on appropriate model parameters. Here we extend these earlier studies by using a large data set of 52 months of buoy observations for a quantitative model verification.

A quantitative measure for the error between simulated and observed trajectories is the displacement which is defined as the distance $\left|\mathbf{x}_{m}(t)-\mathbf{x}_{b}(t)\right|$ between the position $\mathbf{x}_{m}(t)$ of the simulated buoy and the position $\mathbf{x}_{b}(t)$ of the observed buoy at a time $t$. At the starting point of a trajectory, $t=0$, the positions are identical, that is, $\mathbf{x}_{m}(0) \equiv \mathbf{x}_{b}(0)$. Owing to the errors discussed in section 5 , the position of the simulated buoy diverges from the observation, usually increasing with time. The displacement rate $D$ is the temporal derivative of the displacement. The average displacement rate for a time period $\tau$ from the beginning of a trajectory is

$$
D(\tau)=\frac{\left|\mathbf{x}_{m}(\tau)-\mathbf{x}_{b}(\tau)\right|}{\tau}
$$

This mean displacement rate is the basis for the definition of the error function. A detailed comparison has to consider the following: (1) The error function should represent the whole drift path, that is, the geometrical form of the trajectory. (2) Over long time periods, the errors in the simulated trajectory accumulate. Once the simulated trajectory has significantly drifted away from the observed buoy track, it experiences a different forcing and thus cannot be expected to match the observation accurately. Therefore the observed trajectories over several months are split into smaller time periods of fixed length $\tau$ (trajectory segments), effectively giving a larger number $N$ of shorter trajectories. For each of these segments, the simulated buoy starts at the same location as the observed one. All segments are compared with the observations by the error function $\varepsilon$, defined as the mean displacement rate averaged over all $N$ trajectory segments:

$$
\varepsilon=\frac{1}{N} \sum_{i=1}^{N} D_{i}(\tau)
$$

where $i$ identifies the trajectory segment. $D_{\imath}(\tau)$ is the corresponding displacement rate averaged over a fixed time interval $\tau$.

Since the error $\varepsilon$ depends on $\tau$, the latter has to be chosen appropriatly. A short interval $\tau$ and a correspondingly large number $N$ of segments allows a detailed verification of the geometrical shape of the simulated trajectory. However the daily observational and forcing data carry a significant amount of high-frequency noise that cancels out over longer periods thus not affecting the long-term ice drift. A larger interval $\tau$ acts as a low-pass filter which reduces the effects of shortterm fluctuations that are not relevant to climate studies.

To find a reasonable compromise, the error function $\varepsilon$ for the standard simulation (Figure 1) has been calcu- 
lated for a number of different intervals $\tau$ between 2 and 60 days (Figure 4 ). The mean error $\varepsilon(\tau)$ decreases with increasing time interval $\tau$. The slope of $\varepsilon(\tau)$, that is, $\partial \varepsilon / \partial \tau$, is steeper for short intervals $\tau$. For longer intervals, the error converges toward an asymptotic value. This indicates that short-term fluctuations of sea ice drift, mostly caused by synoptic weather events, contribute significantly to the mean displacement rate for short intervals $\tau$ but cancel out when the mean ice drift over longer periods of several days is considered. As the focus of this large-scale model is the reproduction of the long-term ice drift on timescales of weeks to months, we use an interval $\tau$ of 30 days for the calculation of the error function in the following. Sensitivity tests show that the optimized parameter values do not significantly depend on whether intervals of $10,20,30$, or 60 days are applied.

\section{Optimization Results}

Our first sensitivity study investigates the effect of variations in the atmospheric and oceanic drag coefficients $c_{a}$ and $c_{w}$ on the performance of the model. While all other model parameters are held constant, $c_{a}$ and $c_{w}$ are varied independently over ranges covering the measured values. Coefficient $c_{a}$ is varied between $1.0 \times 10^{-3}$ and $2.8 \times 10^{-3}$ in steps of $0.3 \times 10^{-3}$, and $c_{w}$ is varied between $2.5 \times 10^{-3}$ and $6.5 \times 10^{-3}$ in steps of $0.5 \times 10^{-3}$. The ice strength parameter $P^{*}$ is held constant at $20,000 \mathrm{~N} \mathrm{~m}^{-2}$.

Figure 5 shows the contour lines of the error function for the 63 simulations with varied drag coefficients. A distinct spatial pattern is clearly revealed: There is one single minimum in the two-dimensional space of drag coefficients. This minimum is enclosed by the contour line of an error of $3 \mathrm{~km}$ per day. Our term "optimized model parameters" refers to the area in parameter space

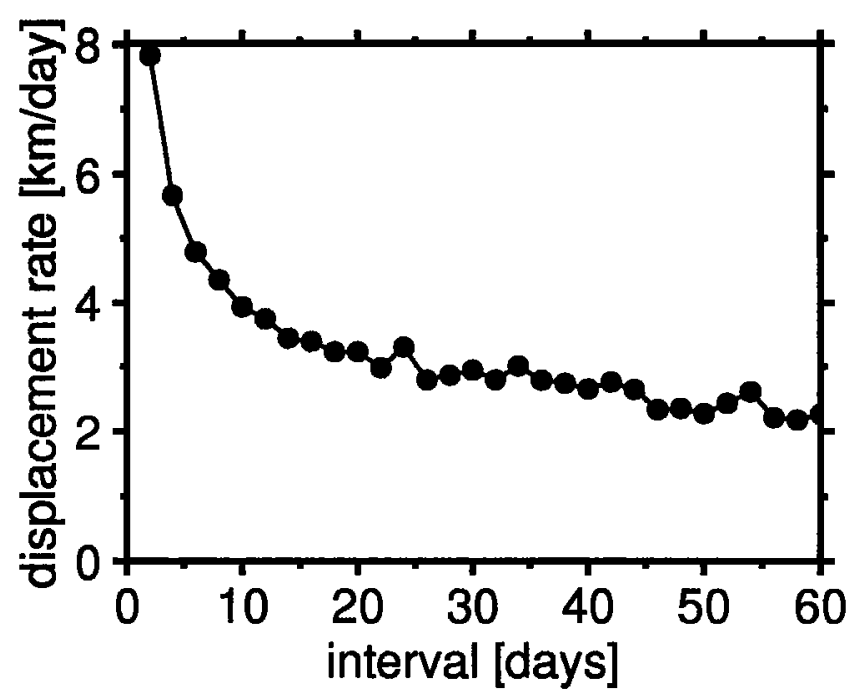

Figure 4. Mean displacement rate [kilometers per day] between all simulated and observed buoys for different trajectory intervals.

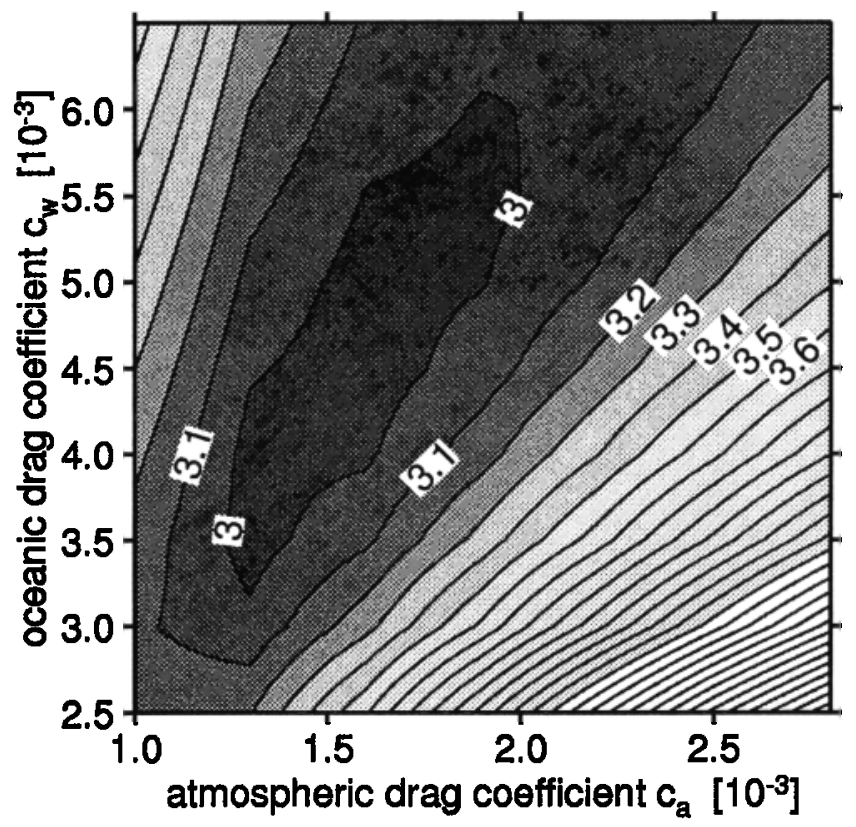

Figure 5. Error function measuring the mean displacement rate between simulated and observed buoy trajectories for varied atmospheric and oceanic drag coefficients $c_{a}$ and $c_{w}$.

where the performance of the model is best rather than refering to specific values. The center of the minimum area is approximately at $c_{a}=1.6 \times 10^{-3}$ and $c_{w}=$ $4.5 \times 10^{-3}$ which we refer to as "optimal" values. The ratio of these optimal drag coefficients is $c_{a} / c_{w} \approx 0.36$.

The error contour line enclosing the minimum area has roughly the shape of an ellipse with a considerable eccentricity. This contour line looks a bit noisy because of the discretization with a finite number of simulations. The major axis of this error ellipse is oriented along a line where the ratio of the drag coefficients is approximately constant. The error function has almost the same value for an atmospheric drag coefficient $c_{a}$ between $1.3 \times 10^{-3}$ and $2.0 \times 10^{-3}$ provided that the oceanic drag coefficient $c_{w}$ increases linearly with increasing $c_{a}$.

Along the direction of the minor axis of the error ellipse, the error function varies much more rapidly than along the direction of the major axis, that is, the gradient is considerably larger. This confirms the statement of $M c P h e e$ [1980] that the ratio of the drag coefficients is much more important than their absolute values, provided the absolute values are within a reasonable range according to observations. This is an important result because it reduces the two model parameters of atmospheric and oceanic drag coefficients essentially to only one, the ratio of the drag coefficients, accompanied by the rather weak requirement that the absolute drag coefficients do not deviate drastically from their optimal values.

The optimal ratio of the drag coefficients $c_{a} / c_{w}$ has been determined with a constant ice strength parameter $P^{*}$. Our second sensitivity study investigates the per- 
formance of the model when the ice strength parameter $P^{*}$ and the ratio of the drag coefficients $c_{a} / c_{w}$ are varied independently. The observational data are from the same six buoys as in the first sensitivity study (Table 1 ). $P^{*}$ is varied between 5000 and $80,000 \mathrm{~N} \mathrm{~m}^{-2}$, and the ratio $c_{a} / c_{w}$ varies between $50 \%$ and $200 \%$ of its standard value of 0.36 . As it is not a priori clear whether this ratio should be modified by varying $c_{a}$ or $c_{w}$, we decide to vary both $c_{a}$ and $c_{w}$ by relative changes of the same magnitude but in opposite directions: A change in the ratio $c_{a} / c_{w}$ by a factor of $k$ is achieved by multiplying $c_{a}$ by $k^{0.5}$ and $c_{w}$ by $k^{-0.5}$.

Figure 6 shows the results of this sensitivity study. Again, there is one single minimum of the error function in this twodimensional parameter space. The contour lines of equal error surrounding this minimum look roughly like ellipses with their major axes oriented along a constant ice strength parameter $P^{*}$ and their minor axes oriented along a constant drag coefficient ratio $c_{a} / c_{w}$. The orientation of these error ellipses indicates a decoupling of the influence of $P^{*}$ and $c_{a} / c_{w}$ on the performance of the model: For any given ratio $c_{a} / c_{w}$ between 0.2 and 0.5 , a $P^{*}$ value of about $20,000 \mathrm{~N} \mathrm{~m}^{-2}$ yields a good performance. Similarly, for a range of values of $P^{*}$ in the vicinity of its optimal value, a ratio of drag coefficients $c_{a} / c_{w}$ close to 0.36 provides for good model performance.

As in our first sensitivity study for $c_{a}$ and $c_{w}$, we note that "optimized parameters" $P^{*}$ and $c_{a} / c_{w}$ do not refer to single values but to an area in parameter space where best results are obtained, while the quality of the simulation reduces significantly if parameter values far off the optimal configuration are used. The area in pa-

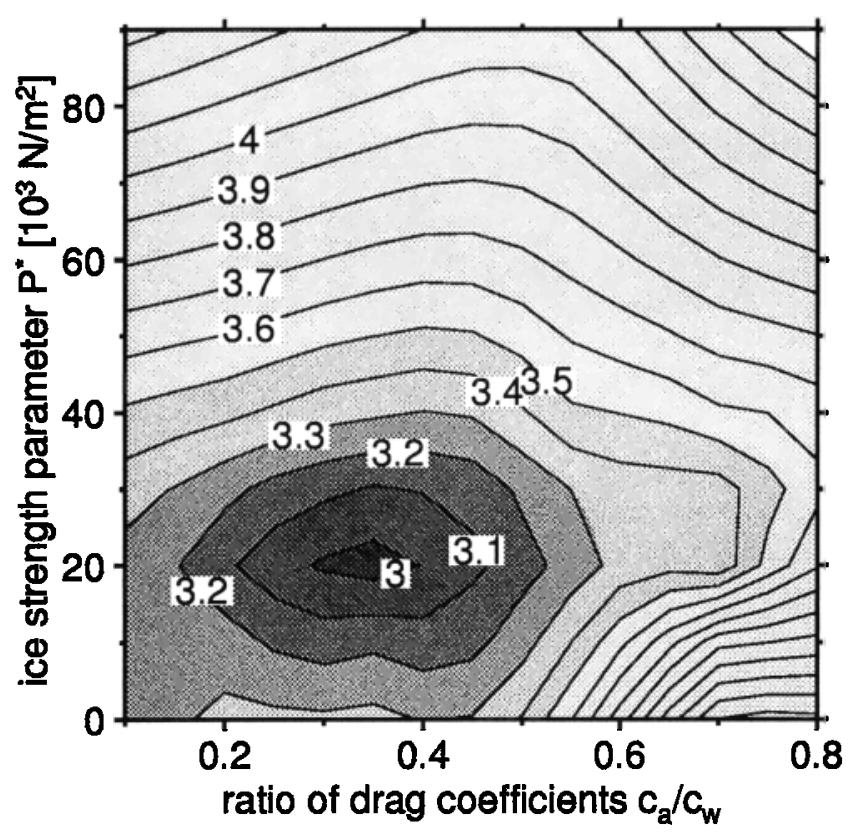

Figure 6. Error function measuring the mean displacement rate between simulated and observed buoy trajectories for varied ice strength $P^{*}$ and ratio of drag coefficients $c_{a} / c_{w}$. rameter space with minimized ice drift error is approximately centered at $c_{a}=1.6 \times 10^{-3}, c_{w}=4.5 \times 10^{-3}$, and $P^{*}=20,000 \mathrm{~N} \mathrm{~m}^{-2}$.

\section{Simulated Sea Ice Transport}

The model in its optimized configuration is now applied to simulate the advection of sea ice in the Weddell Sea and the related freshwater fluxes that are important for the ocean circulation. The excess of locally frozen minus melted ice is measured by the net freezing rate in meters of vertical ice thickness increment per year. It represents a change in sea ice volume per area and time. A positive net freezing rate indicates regions where more ice is frozen than melted in the long-term mean. As the freezing of ice is associated with brine release into the oceanic mixed layer, the net freezing rate can be converted into a negative freshwater flux (similar to evaporation) for given density and salinity of sea ice. For sea ice with a density of $900 \mathrm{~kg} \mathrm{~m}^{-3}$ and a salinity of 5 practical salinity units, a net freezing rate of $1 \mathrm{~m}$ of ice per year is equivalent to a loss of about $0.77 \mathrm{~m}$ of freshwater per year out of the liquid oceanic mixed layer.

Figure 7 shows the spatial pattern of the simulated net freezing rate for 1986 and 1987. The general pattern is similar for both years: dipole with net freezing in the southern Weddell Sea and net melting in the north. The magnitude of the dipole, indicated by the maximum absolute values of the net freezing rate, is stronger in 1987 than in 1986. Highest simulated net freezing rates of more than $2 \mathrm{~m}$ per year occur in the southern Weddell Sea (Figure $7 b$ ). The negative net freezing rate in the northern Weddell Sea indicates a net melting of sea ice also up to more than $2 \mathrm{~m}$ per year. The associated freshwater flux is considerably larger than precipitation minus evaporation. This shows the importance of sea ice transports for the freshwater balance and the hydrological cycle in polar regions.

The spatial pattern of the net freezing rate is maintained by a mean transport of sea ice from the southern freezing regions to the northern melting regions in the cyclonic Weddell Gyre. This process is similar to the sea ice transport through Fram Strait which maintains a pattern with net freezing in the Arctic Ocean and net melting in the Greenland-Iceland-Norwegian Sea [e.g., Aagaard and Carmack, 1989; Harder et al., 1998].

To derive the magnitude and spatial pattern of sea ice transport, we define a zonal section along $68.75^{\circ} \mathrm{S}$ that cuts through the Weddell Gyre and approximately separates latitudes of net freezing or melting. As the lateral boundaries of this cross section are land, this line is the only open boundary across which the southern Weddell Sea exchanges sea ice with surrounding areas. The northward ice volume transport is calculated for each model grid cell along this line. The spatially integrated sea ice transport across this section is the net ice volume transport out of the southern Weddell Sea into the Antarctic Circumpolar Current. 

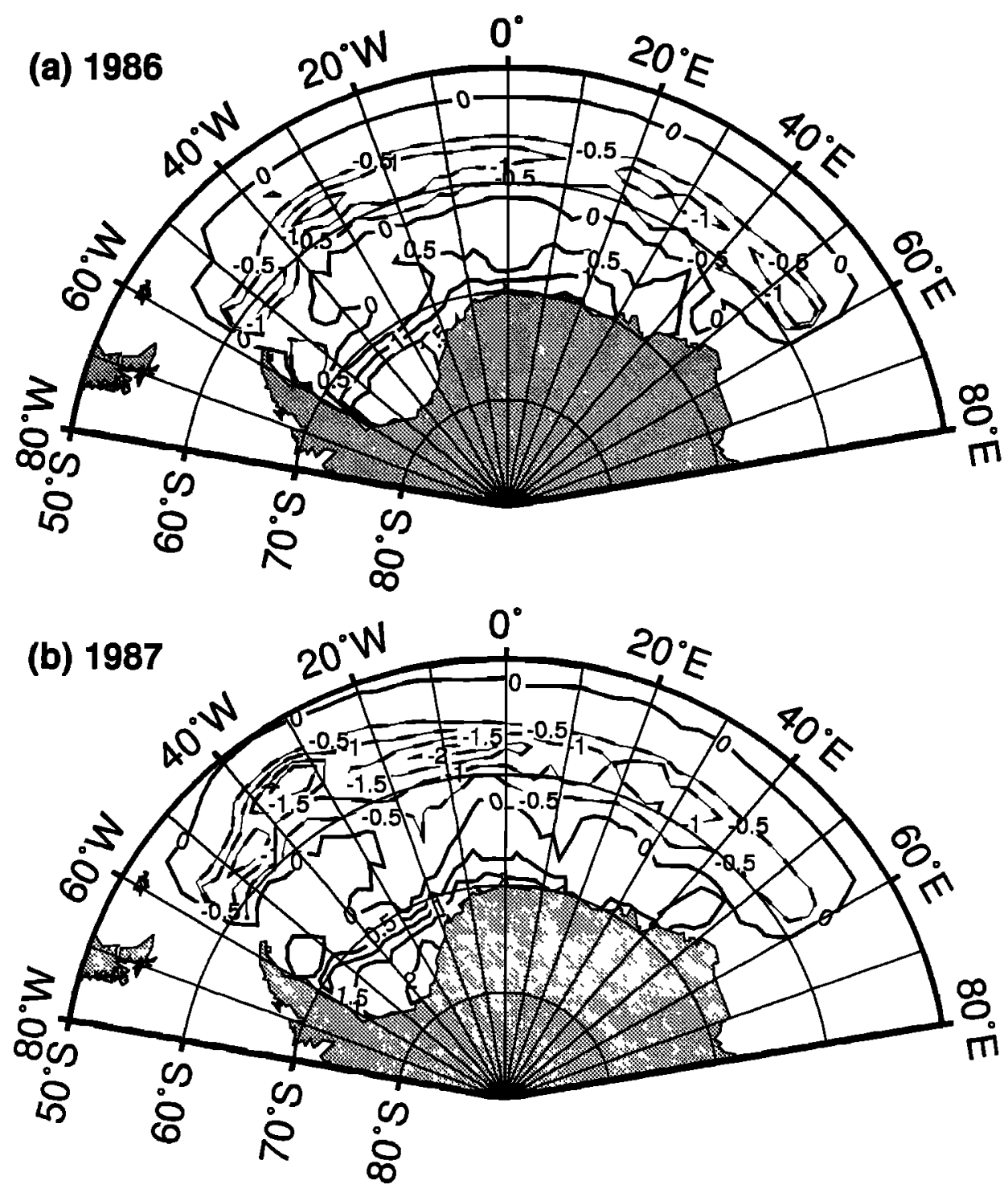

Figure 7. Annual means of net freezing rate (meters of locally frozen sea ice per year) for (a) 1986 and (b) 1987. Negative values (dashed contour lines) indicate net melting.

Figure 8 shows the annual mean of the simulated northward sea ice transport across all grid boxes on this section for 1986 and 1987. A positive sign of northward transport represents an export out of the southern Weddell Sea. The general spatial pattern is a northward transport (export) in the western Weddell Sea and a southward transport (import) in its eastern region. The export exceeds the import both in magnitude (i.e., volume) and in the number of grid cells involved (i.e., area). Strongest exports are found for the three westernmost grid cells. The biannual mean 1986/1987 of net sea ice export out of the southern Weddell Sea integrated across the section is $2016 \mathrm{~km}^{3}$ per year. It is established by a mean export of $2201 \mathrm{~km}^{3}$ per year in the west minus a mean import of $185 \mathrm{~km}^{3}$ per year in the east. The dominating term for the ice volume transport is the export, while the import with the southward recirculation in the eastern Weddell sea modifies the advection balance by only about $10 \%$.
A comparison of the simulation results for 1986 and 1987 (Figure 8) gives a qualitative estimate of interannual variations in sea ice transport. The general pattern of export in the west and import in the east, and especially strong export along the Antarctic Peninsula, is similar for 1986 and 1987 . However, the center of the gyre, defined by the longitude where the transport changes sign, is at $32.5^{\circ} \mathrm{W}$ in 1986 but more eastward at $17.5^{\circ} \mathrm{W}$ in 1987 . Year 1987 shows a stronger export and a smaller import than 1986 . The net northward transport is $1693 \mathrm{~km}^{3}$ in 1986 and $2339 \mathrm{~km}^{3}$ in 1987 . The export in 1987 exceeds the value for 1986 by $646 \mathrm{~km}^{3}$ or about $32 \%$ of the biannual mean value. This indicates that interannual variations in wind forcing cause considerable variability in sea ice transports, which, in turn, affect the net freezing rate, that is, the salt/freshwater flux into the ocean. The stronger export in 1987 causes the more pronounced pattern in the net freezing rate for this year (Figure 7), compared to 1986. 

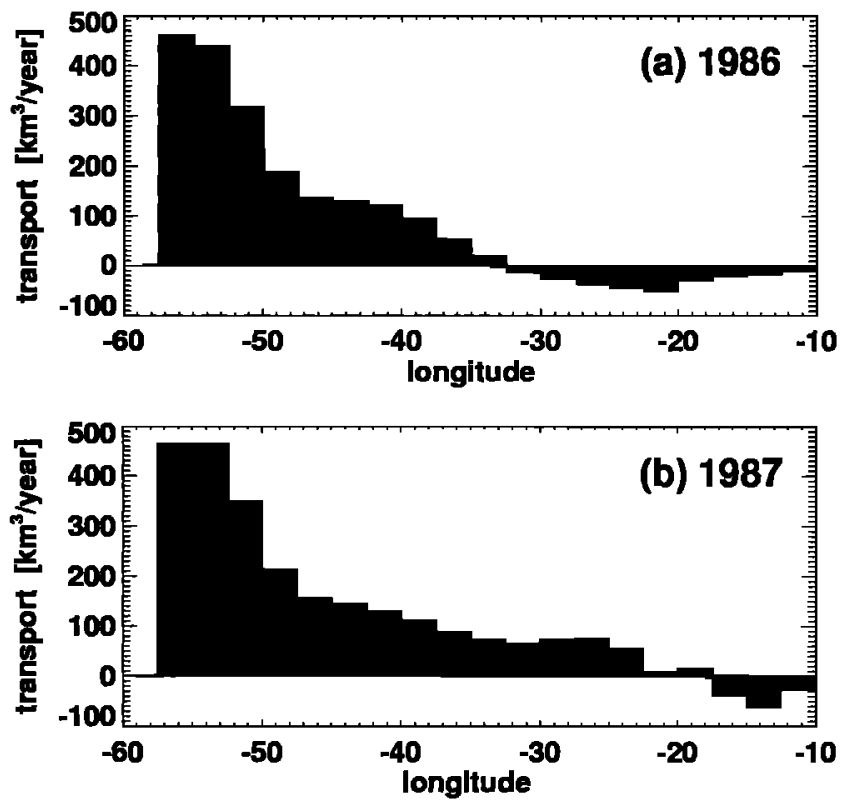

Figure 8. Annual means of northward sea ice volume transport across $68.75^{\circ} \mathrm{S}$ for (a) 1986 and (b) 1987. Negative values represent southward transport.

\section{Discussion and Conclusions}

The transport of sea ice in the gyre of the Weddell Sea in 1986 and 1987 has been investigated with an optimized sea ice model. The model configuration relies on three components: (1) The model physics of this dynamic-thermodynamic sea ice model with a viscousplastic rheology has performed best in the hierarchy of models investigated by the Sea Ice Model Intercomparison Project [Lemke et al., 1997; Kreyscher et al., 1997; Harder 1997]. (2) Daily atmospheric forcing derived from ECMWF analyses for 1986/1987 provides for much more realistic boundary conditions than previous studies with climatological forcing [e.g., Hibler, 1979]. (3) A large amount of observed sea ice drift data is used to assess the accuracy of the model quantitatively.

The simulated annual northward ice-volume transport of about $2000 \mathrm{~km}^{3}$ per year out of the southern Weddell Sea is of a similar magnitude as the sea ice transport through Fram Strait in the Northern Hemisphere. Compared to river runoffs, these sea ice transports almost reach the largest freshwater flux on Earth, the outflow of the Amazon River. A comparison of the export in two different years gives a first indication of its strong interannual variability, in this case exceeding $30 \%$ of the biannual mean.

Experiments covering longer periods are required for reliable statistics of the variability of this freshwater flux on seasonal to decadal timescales. The 40-year simulations with forcing from the National Centers for Environmental Prediction/National Center for Atmospheric Research Reanalyses Project have already been performed for the Northern Hemisphere and show considerable variability on multiyear timescales [e.g., Hilmer et al., 1998]. Applying this type of forcing to the Wed- dell Sea is investigated by Windmüller [1997] and Voß [1998].

The sensitivity study with varied atmospheric and oceanic drag coefficients shows that these parameters strongly affect the ice drift and should be set carefully. Further, the simulated velocities are more sensitive to the ratio of the drag coefficients than to their absolute values, provided the latter are in a reasonable range. This has been suggested by McPhee [1980] based on measurements, and here also turns out to be valid for the model. A second sensitivity study shows that the ice strength parameter also has considerable influence on the ice drift. Its optimal value is almost independent of the ratio of the drag coefficients. Both sensitivity studies together show that the model results are in best agreement with observed ice drift when the atmospheric and oceanic drag coefficients are $c_{a}=1.6 \times 10^{-3}$ and $c_{w}=4.5 \times 10^{-3}$ and the ice strength parameter is $P^{*}=20,000 \mathrm{~N} \mathrm{~m}^{-2}$. Slightly varying these parameters does not significantly affect the performance of the model, while larger modifications, for example, by a factor of 2 , disturb the simulation results.

As this study applies a fixed ocean current, the question of how well these parameters are expected to perform in an interactive, coupled ice-ocean model arises. First, we emphasize that the aim of this study is to demonstrate a way to validate sea ice models with observed drift data, rather than deriving "universal" constants for parameterizations of subscale processes. If a strongly different type of forcing is applied to the ice, such as an interactive ocean, we suggest repeating the comparison with observed buoy drift. Second, as the dynamic inertia of the upper ocean is considerably larger than the inertia of sea ice, the response of the ocean to external forcing, such as wind stress, will be much slower than the reaction of sea ice drift. This difference in timescales suggests that the assumption of a steady ocean current may be a useful firstorder approximation. Third, a repetition of the experiments with a fully coupled atmosphere-ice-ocean model is certainly desirable. However, this would not only require an excessive computational cost for more than a hundred sensitivity studies but also presents the difficulty of obtaining reliable, observed ocean currents in the Southern Ocean as verification data.

Recently, Geiger et al. [1998] published an interesting investigation similar to our study. They compare results from a stand-alone sea ice model with the observed drift of a buoy array deployed in 1992 around Ice Station Weddell 1. They apply 10 different error functions based not only on drift speed and direction but also on spatial derivatives of the ice velocity field, such as divergence or vorticity. Similarly to our study, they investigate the effect of modifying the ratio of drag coefficients for two different cases and of applying a number of different ice rheologies.

First, they show that increasing the ratio of drag coefficients from 0.22 as used by Hibler [1979] to 0.5 following Fischer and Lemke [1994] has a stronger impact on 
the majority (7 out of 10) of their error functions than any other tested modification of rheology or model resolution. Thus the importance of the ratio of drag coefficients demonstrated in our study is also shown by Geiger et al. [1998].

Second, the inconclusive outcome was that four of their error functions improved significantly with a ratio $c_{a} / c_{w}=0.5$, while three got worse. We note that our study derived an "optimal" ratio of drag coefficients of about 0.36 , which is in the middle between the two cases tested by Geiger et al. [1998]. This suggests that it would be valuable to repeat the investigation of Geiger et al. [1998] with more sensitivity runs of varied drag coefficients, including the optimized values of our study. Using the spatial derivatives of the ice velocity field as additional error functions will be especially useful when more observational data of these derivates become available not only from buoy arrays but also from satellite imagery.

Acknowledgments. Thanks are due to Ch. Kottmeier, D. Crane, and H. Hoeber for providing the Argos buoy data. We thank H. Eicken, H. Hellmer, Ch. Kottmeier, P. Lemke, D. Martinson, and the anonymous reviewers for their helpful comments. Atmospheric forcing data were partially derived from ECMWF analyses. Typesetting was performed with the $\mathrm{TEX}_{\mathrm{E}} / \mathrm{IAT}_{\mathrm{EX}} \mathrm{x}$ software of Donald E. Knuth and Leslie Lamport. Several figures were prepared with the GMT software [Wessel and Smith, 1991].

\section{References}

Aagaard, K., and E. C. Carmack, The role of sea ice and other fresh water in the Arctic circulation, J. Geophys. Res., 94(C10), 14485-14498, 1989.

Andreas, E. L., and K. J. Claffey, Air-ice drag coefficients in the western Weddell Sea, 1. Values deduced from profile measurements, J. Geophys. Res., 100(C3), 4821-4831, 1995.

Andreas, E. L., W. B. Tucker III, and S. F. Ackley, Atmospheric boundary-layer modification, drag coefficient, and surface heat flux in the Antarctic marginal ice zone, $J$. Geophys. Res., 89(C1), 649-661, 1984.

Andreas, E. L., M. A. Lange, S. F. Ackley, and P. Wadhams, Roughness of Weddell Sea ice and estimates of the air-ice drag coefficient, J. Geophys. Res., 98(C7), 12439-12452, 1993.

Argos Collect Localisation Satellites Company, User Manual, Toulouse, France, 1988.

Arya, S. P. S., A drag partition theory for determining the large-scale roughness parameter and wind stress on the Arctic pack ice, J. Geophys. Res., 80(24), 3447-3454, 1975.

Campbell, W. J., The wind-driven circulation of ice and water in a polar ocean, J. Geophys. Res., $70(14), 3279$ 3301, 1965.

Chapman, W. L., W. J. Welch, K. P. Bowman, J. Sacks, and J. E. Walsh, Arctic sea ice variability: Model sensitivities and a multidecadal simulation, $J$. Geophys. Res., $99(\mathrm{C} 1)$, 919-935, 1994.

Drinkwater, M. R., H. Fischer, M. Kreyscher, and M. Harder, Comparison of seasonal sea-ice model results with satellite microwave data in the Weddell Sea, paper presented at the IGARSS Conference 1995 on Recent Ad- vances in Remote Sensing/Modelling of Sea Ice, Int. Geosci. and Remote Sens. Symp., Florence, Italy, 1995.

Fischer, H., Vergleichende Untersuchungen eines optimierten dynamisch-thermodynamischen Meereismodells mit Beobachtungen im Weddellmeer, Ber. Polarforsch. 166, Alfred-Wegener-Inst. für Polar- und Meeresforsch., Bremerhaven, Germany, 1995.

Fischer, H., and P. Lemke, On the required accuracy of atmospheric forcing fields for driving dynamic-thermodynamic sea ice models, in The Polar Oceans and Their Role in Shaping the Global Environment, Geophys. Monogr. Ser., vol. 85, edited by O. M. Johannessen, R. D. Muench, and J. E. Overland, pp. 373--381, AGU, Washington, D. C., 1994.

Flato, G. M., and W. D. Hibler III, On a simple sea-ice dynamics model for climate studies, Ann. Glaciol., 14, 72-77, 1990.

Flato, G. M., and W. D. Hibler III, Ridging and strength in modeling the thickness distribution of Arctic sea ice, $J$. Geophys. Res., 100(C9), 18611-18626, 1995.

Geiger, D. A., W. D. Hibler III, and S. F. Ackley, Largescale sea ice drift and deformation: Comparison between models and observations in the Weddell Sea during 1992, J. Geophys. Res., 103(C10), 21893-21914, 1998.

Hanssen-Bauer, I., and Y. T. Gjessing, Observations and model calculations of aerodynamic drag on sea ice in the Fram Strait, Tellus, Ser. A, 40, 151-161, 1988.

Harder, M., Erweiterung eines dynamisch-thermodynamischen Meereismodells zur Erfassung deformierten Eises, Ber. Fachberezch Phys. 50, Alfred-Wegener-Inst. für Polar- und Meeresforsch., Bremerhaven, Germany, 1994.

Harder, M., Dynamik, Rauhigkeit und Alter des Meereises in der Arktis - Numerische Untersuchungen mit einem großskaligen Modell, Ber. Polarforsch. 203, AlfredWegener-Inst. für Polar- und Meeresforsch., Bremerhaven, Germany, 1996.

Harder, M., Roughness, age and drift trajectories of sea ice in large-scale simulations and their use in model verifications, Ann. Glaciol. 25, 237-240, 1997.

Harder, M., and P. Lemke, Modelling the extent of sea ice ridging in the Weddell Sea, in The Polar Oceans and Their Role in Shaping the Global Environment, Geophys. Monogr. Ser., vol. 85, pp. 187-197, AGU, Washington, D.C., 1994.

Harder, M., P. Lemke, and M. Hilmer, Simulation of sea ice transport through Fram Strait - Natural variability and sensitivity to forcing, J. Geophys. Res., 103(C3), 5595$5606,1998$.

Hartmann, J., C. Kottmeier, C. Wamser, and E. Augstein, Aircraft measured atmospheric momentum, heat and radiation fluxes over Arctic sea ice, in The Polar Oceans and Their Role in Shaping the Global Environment, Geophys. Monogr. Ser., vol. 85, pp. 443-454, AGU, Washington, D.C., 1994.

Hibler, W. D. III, A dynamic thermodynamic sea ice model, J. Phys. Oceanogr., 9(4), 815-846, 1979.

Hibler, W. D. III., and S. F. Ackley, Numerical simulation of the Weddell Sea pack ice, J. Geophys. Res., 88(C5), 2873-2887, 1983.

Hilmer, M., M. Harder, and P. Lemke, Sea ice transport: a highly variable link between Arctic and North Atlantic, Geophys. Res. Lett., 25(17), 3359-3362, 1998.

Hoeber, H., Sea ice dynamics in the Weddell Sea in winter, Ann. Glaciol., 15, 9-16, 1991.

Hoeber, H., and M. Gube-Lehnhardt, The eastern Weddell Sea drifting buoy data set of the Winter Weddell Sea Project (WWSP) 1986, Ber. Polarforsch. 37, AlfredWegener-Inst. für Polar- und Meeresforsch., Bremerhaven, Germany, 1987.

Holland, D. M., L. A. Mysak, D. K. Manak, and J. M. Ober- 
huber, Sensitivity study of a dynamic thermodynamic sea ice model, J. Geophys. Res., 98(C2), 2561-2586, 1993.

Ip, C. F., W. D. Hibler III, and G. M. Flato, On the effect of rheology on seasonal sea-ice simulations, Ann. Glaciol., $15,17-25,1991$.

Ip, C. F., Numerical investigation of different rheologies on sea ice dynamics, Ph.D. thesis, 242 pp., Thayer School of Eng., Dartmouth Coll., Hanover, N. H., 1993.

Kottmeier, Ch., and D. Engelbart, Generation and atmospheric heat exchange of coastal polynyas in the Weddell Sea, Boundary Layer Meteorol., 60, 207-234, 1992.

Kottmeier, Ch., and R. Hartig, Winter observations of the atmosphere above Antarctic sea ice, J. Geophys. Res., 95(D10), 16551-16560, 1990.

Kottmeier, Ch., and L. Sellmann, Atmospheric and oceanic forcing of Weddell Sea ice motion, J. Geophys. Res., 101(C9), 20809-20824, 1996.

Kottmeier, Ch., J. Olf, W. Frieden, and R. Roth, Wind forcing and ice motion in the Weddell Sea, J. Geophys. Res., 97(D18), 20373-20383, 1992.

Kreyscher, M., M. Harder, and P. Lemke, First results of the Sea Ice Model Intercomparison Project (SIMIP), Ann. Glaciol., 25, 8-11, 1997.

Lemke, P., W. B. Owens, and W. D. Hibler III, A coupled sea ice - mixed layer - pycnocline model for the Weddell Sea, J. Geophys. Res., 95(C6), 9513-9525, 1990.

Lemke, P., W. D. Hibler III, G. M. Flato, M. Harder, and M. Kreyscher, On the improvement of sea ice models for climate simulations: The Sea Ice Model Intercomparison Project (SIMIP), Ann. Glaciol., 25, 183-187, 1997.

Leppäranta, M., On the structure and mechanics of pack ice in the Bothnian Bay, Finn. Mar. Res., 248, 3-86, 1981.

Lu, Q.-M., J. Larsen, and P. Tryde, A dynamic and thermodynamic sea ice model for subpolar regions, $J$. Geophys. Res., 95(C8), 13433-13457, 1990.

Mai, S., C. Wamser, and C. Kottmeier, Geometric and aerodynamic roughness of sea ice, Boundary Layer Meteorol., 77, 233-248, 1996.

Massom, R., Observing the advection of sea ice in the Weddell Sea using buoy and satellite passive microwave data, J. Geophys. Res., 97(C10), 15559-15572, 1992.

$\mathrm{McPhee}, \mathrm{M}$. G., The effect of the oceanic boundary layer on the mean drift of pack ice: Application of a simple model, J. Phys. Oceanogr., 9, 388-400, 1979.

McPhee, M. G., An analysis of pack ice drift in summer, in Sea Ice Processes and Models, edited by R. S. Pritchard, Univ. of Wash. Press, Seattle, 1980.

McPhee, M. G., and D. G. Martinson, Turbulent mixing under drifting pack ice in the Weddell Sea, Science, 263, 218-221, 1994.

McPhee, M. G., and J. D. Smith, Measurements of the turbulent boudndary layer under pack ice, J. Phys. Oceanogr. 6, 696-711, 1976.

Overland, J. E., Atmospheric boundary layer structure and drag coefficients over sea ice, J. Geophys. Res., 90(C5), 9029-9049, 1985.

Overland, J. E., and R. Colony, Geostrophic drag coefficients for the central Arctic derived from Soviet drifting station data, Tellus, Ser. A, 46, 75-85, 1994.

Overland, J. E., and C. H. Pease, Modeling ice dynamics of coastal seas, J. Geophys. Res., 93, 15619-15637, 1988.

Owens, W. B., and P. Lemke, Sensitivity studies with a sea ice-mixed layer-pycnocline model in the Weddell Sea, $J$. Geophys. Res., 95(C6), 9527-9538, 1990.

Parkinson, C. L., and W. M. Washington, A large-scale numerical model of sea ice, J. Geophys. Res., 84(C1), 311337, 1979.

Piacsek, S., R. Allard, and A. Warn-Varnas, Studies of the Arctic ice cover and upper ocean with a coupled ice-ocean model, J. Geophys. Res., 96(C3), 4631-4650, 1991.
Preller, R., and P. G. Posey, A numerical model of a summer reversal of the Beaufort Gyre, Geophys. Res. Lett., 16(1), 69-72, 1989.

Richter-Menge, J. A., Towards improving the physical basis for ice-dynamics models, Ann. Glaciol. 25, 177-182, 1997.

Rowe, M. A., C. B. Sear, S. J. Morrison, P. Wadhams, D. W. S. Limbert, and D. R. J. Crane, Periodic motions in Weddell sea pack ice, Ann. Glaciol., 12, 145-151, 1989.

Semtner, A. J., Jr., A model for the thermodynamic growth of sea ice in numerical investigations of climate, J. Phys. Oceanogr., 6, 379-389, 1976.

Smith, S. D., Coefficients for sea surface wind stress, heat flux, and wind profiles as a function of wind speed and temperature, J. Geophys. Res., 93(C12), 15467-15472, 1988.

Steele, M., J. H. Morison, and N. Untersteiner, The partition of air-ice-ocean momentum exchange as a function of ice concentration, floe size, and draft, J. Geophys. Res., 94(C9), 12739-12750, 1989.

Steele, M., J. Zhang, D. Rothrock, and H. Stern, The force balance of sea ice in a numerical model of the Arctic Ocean, J. Geophys. Res., 102, 21061-21079, 1997.

Stössel, A., Application of an atmospheric boundary layer model to a large-scale coupled sea-ice-oceanic mixed layer model for the Southern Ocean, Ann. Glaciol., 15, 191$195,1991$.

Stössel, A., Sensitivity of Southern Ocean sea-ice simulations to different atmospheric forcing algorithms, Tellus, Ser. $A, 44,395-413,1992$.

Stössel, A., and M. Claussen, On the momentum forcing of a large-scale sea-ice model, Clim. Dyn., 9, 71-80, 1993

Stössel, A., P. Lemke, and W. B. Owens, Coupled sea icemixed layer simulations for the Southern Ocean, J. Geophys. Res., 95(C6), 9539-9555, 1990.

Thorndike, A. S., and R. Colony, Sea ice motion in response to geostrophic winds, J. Geophys. Res., 87(C8), 5845$5852,1982$.

Tremblay, L.-B., and L. A. Mysak, The possible effects of including ridge-related roughness in air-ice drag parameterization: A sensitivity study, Ann. Glaciol., 25, 22-25, 1997.

Trenberth, K. E., and J. G. Olson, ECMWF Global analyses 1979-1986: Circulation statistics and data evaluation, Tech. Note $T N-300+S T R$, Nat. Cent. for Atmos. Res. (NCAR), Boulder, Colo., 1988.

Vihma, T., and J. Launiainen, Ice drift in the Weddell Sea in 1990-1991 as tracked by a satellite buoy, J. Geophys. Res., 98(C8), 14471-14485, 1993.

VoB, S., Variabilität der Meereisdecke im Weddellmeer in Modell- und Satellitendaten, Masters thesis, Inst. für Meereskunde, Kiel, Germany, 1998.

Wamser, C., and D. G. Martinson, Drag coefficients for winter Antarctic pack ice, J. Geophys. Res., g8(C7), 1243112437, 1993.

Wessel, P., and W. H. F. Smith, Free software helps map and display data, Eos Trans. AGU, 72, 445-446, 1991.

Windmüller, M., Untersuchung von atmosphärischen Reanalysedaten im Weddellmeer und Anwendung auf ein dynamisch-thermodynamisches Meereismodell, Masters thesis, 66 pp., Inst. für Meereskunde, Kiel, Germany, 1997.

M. Harder, Institut für Meereskunde an der Universität Kiel, Düsternbrooker Weg 20, D-24105 Kiel, Germany. (mharder@ifm.uni-kiel.de)

H. Fischer, Alfred-Wegener-Institut für Polar- und Meeresforschung, Columbusstrasse, D-27568 Bremerhaven, Germany.

(Received July 24, 1998; revised November 4, 1998; accepted February 12, 1999.) 